\title{
On Line Polling Information System
}

\author{
Ashok Kumar B \\ Pondicherry University, Karaikal Campus, Karaikal \\ Email: bashokresearch@gmail.com \\ Dr. S. Bhuvaneswari (Corresponding Author) \\ Pondicherry University, Karaikal Campus, Karaikal \\ Email: booni_67@yahoo.co.in
}

Received: October 12, 2011 Accepted: November 09, 2011 DOI: 10.5296/jpag.v1i2.1128

\begin{abstract}
In a social democratic set up voting is one of our fundamental duties as responsible citizens of the country. But nowhere around a $100 \%$ people come to vote during the elections in their territory. Net savvy new generation want manual free voting system. Survey says pubic need a system on their hands reach through which they can vote. Keeping this as objective this via net based Information System is engineered.
\end{abstract}

Keywords: Corporate Governance, SME, Norms 


\section{Macrothink}

\section{Introduction}

The purpose of this system is to design and develop the application of On Line National Polling through which one can vote on line to the contestant he wishes. While making a request to the system for on line voting the system generates the Vote rid by which the user casts his vote. This system also provides the facility that displays e-results by constitution wise. The existing manual system making use of polling booths is totally time driven which is not that of the present.

\section{Solution of These Problems}

- Reliability: The project performs intended function with required precision; hence this project is very reliable.

- Feasibility: The project maintenance is easy and modifications can be made in the existing system in future. All data is centralized.

- Online Processing: The online processing of the project is very simple following the existing manual method without changes and suitable validation is provided for the easy and correct access of users.

- Security: Security measures are taken to avoid mishandling of database. Password restrictions are provided to enter into database.

\section{Proposed System}

The problems in the existing system are taken back in the new by the designed interface having flexibility of online registration cum voting. The system displays the e results after the user has voted. The facility to check the status details of the user and visinity of the candidates for nominations are the key factors of the interface.

\section{Process Models Used}

\section{SDLC Model:}

\section{Software Development Life Cycle (SDLC)}

The Software Development Lifecycle (SDLC) for small to medium database application development efforts.

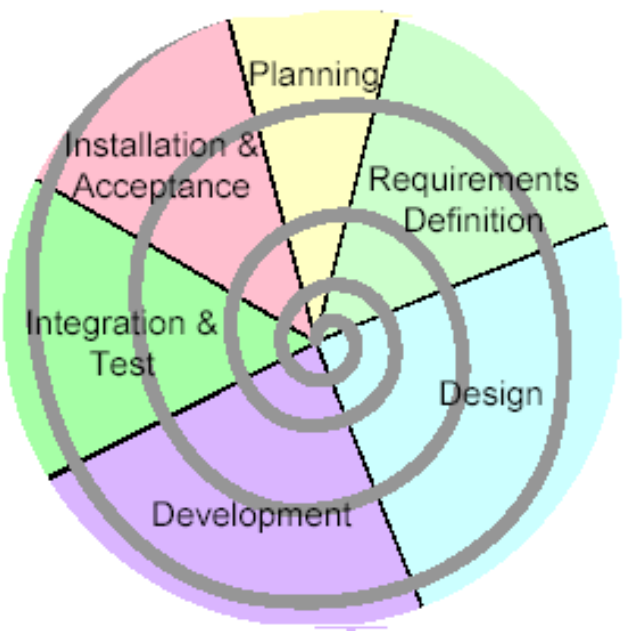


This project uses iterative development lifecycle, where components of the application are developed through a series of hard iteration.

\section{Hardware Requirements}

\begin{tabular}{|l|l|}
\hline Content & Description \\
\hline HDD & $\begin{array}{l}20 \text { GB Min } \\
40 \text { GB Recommended }\end{array}$ \\
\hline RAM & $\begin{array}{l}512 \text { GB Min } \\
1 \text { GB Recommended }\end{array}$ \\
\hline
\end{tabular}

\section{Software Requirements}

\begin{tabular}{|l|l|}
\hline Content & Description \\
\hline OS & Windows XP with SP2 or Windows Vista \\
\hline Database & MS-SQL server 2005 \\
\hline Technologies & ASP.NET with C\#.NET \\
\hline IDE & Ms-Visual Studio .Net 2008 \\
\hline Browser & IE \\
\hline
\end{tabular}




\begin{tabular}{|l|l|c|}
\hline \multicolumn{1}{|c|}{ Coldumn Name } & \multicolumn{1}{|c|}{ Data Type } & Allow Nulls \\
\hline C UserName & varchar(50) & $\square$ \\
\hline Password & varchar(50) & $\square$ \\
\hline Role & varchar(50) & $\square$ \\
\hline UserId & int & $\square$ \\
\hline & & $\square$ \\
\hline
\end{tabular}

Table :1 Administrator login to view and update details of voters and their nominees.

\begin{tabular}{|l|l|c|}
\hline \multicolumn{3}{|c|}{ tblVoterRegistration } \\
\hline SNo & \multicolumn{1}{|c|}{ Data Type } & Allow Nulls \\
\hline VoterId & int & $\square$ \\
\hline FName & varchar(50) & $\square$ \\
\hline LName & varchar(50) & $\square$ \\
\hline FatherName & varchar(50) & $\square$ \\
\hline DOB & varchar(50) & $\square$ \\
\hline DOR & datetime & $\square$ \\
\hline Address & datetime & $\square$ \\
\hline ConstitutionID & varchar(200) & $\square$ \\
\hline EMailiD & int & $\square$ \\
\hline ContactNo & varchar(100) & $\square$ \\
\hline ElectionMode & bigint & $\square$ \\
\hline Photo & varchar(50) & $\square$ \\
\hline PhotoFileName & varbinary(MAX) & $\square$ \\
\hline Status & varchar(100) & $\square$ \\
\hline & varchar(100) & $\square$ \\
\hline
\end{tabular}

Table :2 Voter register online by specifying his/her Full name,Father name, Date of Birth, address, Email ID etc .After registering user would be given VoterID through which he can vote a particular candidate. 


\section{Macrothink}

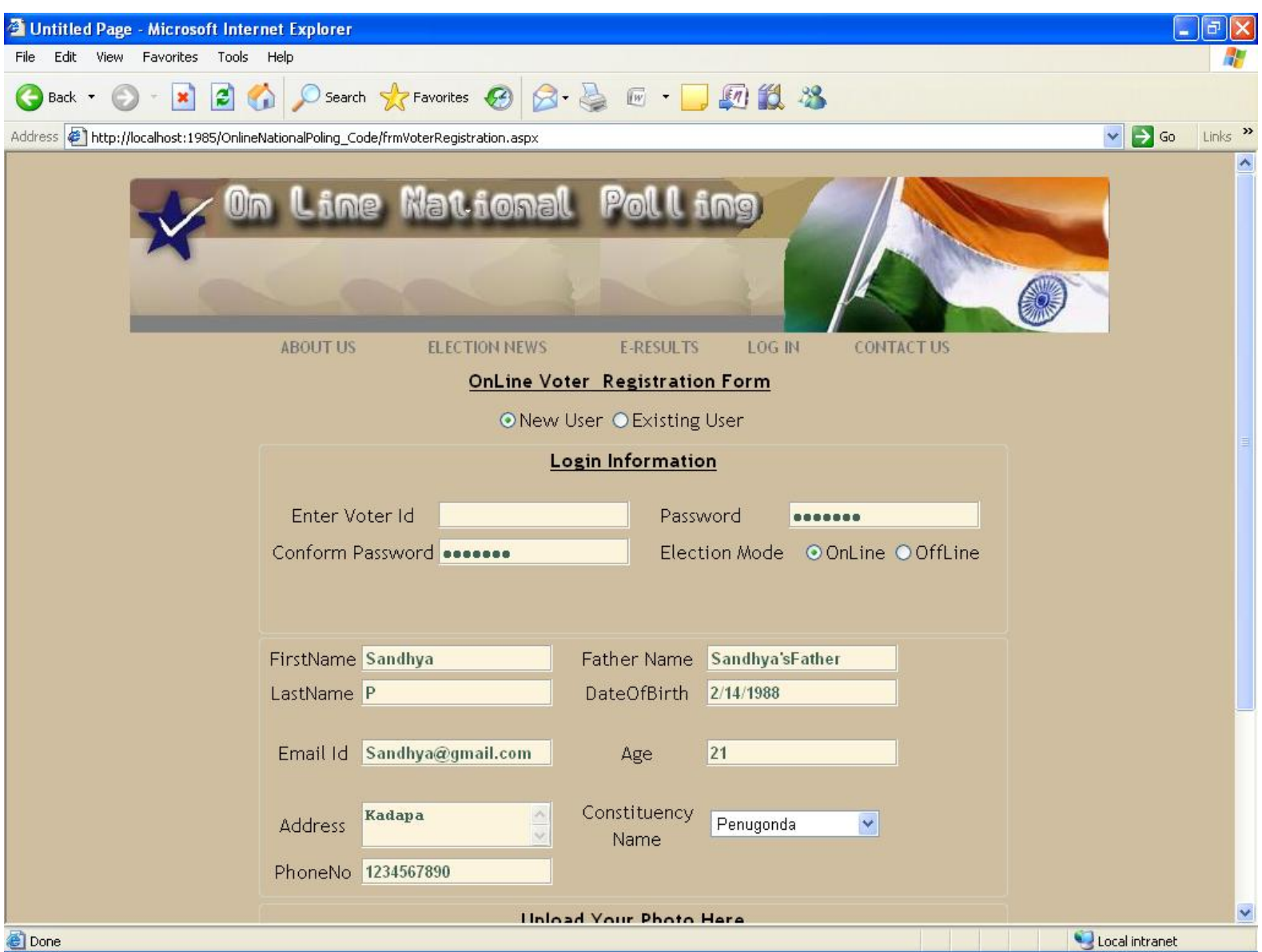

Figure :1 Interface where the user enters input for registering online where he/she would be given VoterID through which the user can vote to particular candidate. 


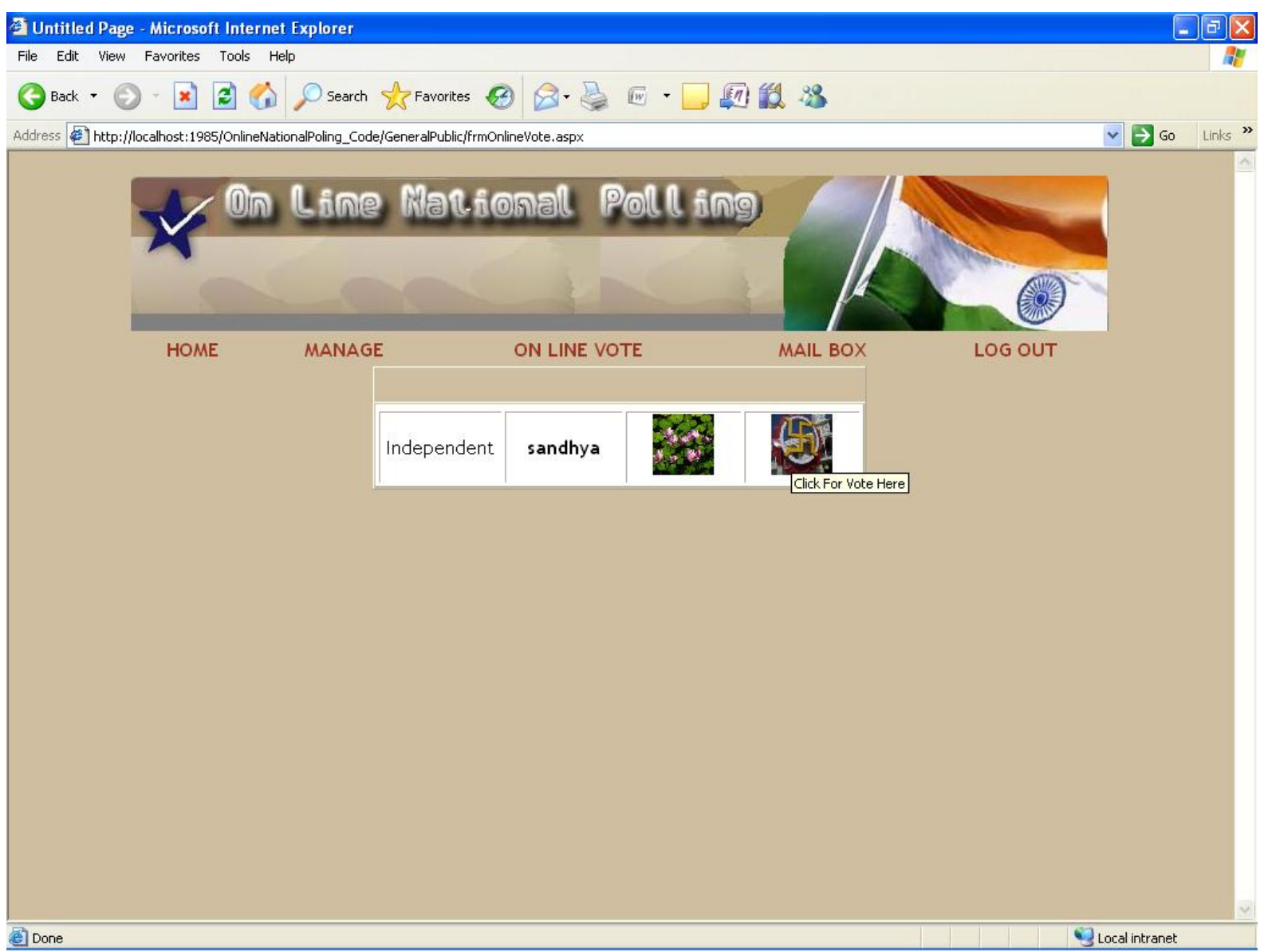

Figure :2 Here voter vote for a candidate through the voter's Voter ID

\section{Benefits of the System:}

The work is identified by the merits of the system offered to the user. The merits are as follows: -

- It's a web-enabled project.

- This project offers user to enter the data through simple and interactive forms.

- The user is mainly more concerned about the validity of the data, whatever he is entering. There are checks on every stages of any new creation, data entry or updation so that the user cannot enter the invalid data, which can create problems at later date.

- User is provided the option of monitoring the records he entered earlier. He can see the desired records with the variety of options provided by him.

- Data storage and retrieval will become faster and easier to maintain because data is stored in a systematic manner and in a single database.

- Through these features it will increase the efficiency, accuracy and transparency. 


\section{Macrothink \\ Journal of Public Administration and Governance \\ ISSN 2161-7104 \\ 2011, Vol. 1, No. 2}

\section{Limitations of the System:}

- The size of the database increases day-by-day, increasing the load on the database back up and data maintenance activity.

- Training for simple computer operations is necessary for the users working on the system.

\section{Conclusion}

It provides knowledge about the latest technology used in developing web enabled application and client server technology that will be great demand in future. This will provide better opportunities and guidance in future in developing projects independently in area of e-governance.

\section{References}

- System Analysis and Design by Senn

- Database System Design by Elmasree Korth

- Software Engineering Concepts by Robert Pressman

- Web references

www.support.mircosoft.com

www.developer.com

www. 15 seconds.com

www.msdn.microsoft.com

www.msdn.microsoft.com/net/quickstart/aspplus/default.com

www.asp.net

www.fmexpense.com/quickstart/aspplus/default.com

www.asptoday.com

www.aspfree.com

www.4guysfromrolla.com/index.aspx 